\title{
GESTÃO DA CONSERVAÇÃO DA PEDRA NO PATRIMÔNIO CONSTRUÍDO - QUESTÕES E PROPOSTAS
}

\author{
Catherine J. S. Gallois \\ Arquiteta e Urbanista, IPHAN-RJ, Doutoranda em Arquitetura e Urbanismo do PPGAU-UFF \\ cgallois@id.uff.br
}

Resumo: Este trabalho tem por objetivo apresentar uma reflexão acerca dos desafios que o campo da conservação da pedra enfrenta atualmente no Brasil. Serão apresentadas as premissas das boas práticas de conservação, orientadas por contextos em que todas as obras de conservação e restauro devem, necessariamente, ser precedidas de projeto, no qual o diagnóstico tem função crucial. Explicitará, pois, o papel fundamental do conjunto das atividades que integram o diagnóstico como processo de construção de conhecimento do estado de conservação dos materiais dos bens culturais imóveis, incluindo os materiais pétreos presentes nos seus sistemas construtivos. Serão também abordadas a legislação e as metodologias disponíveis e discutidas as vantagens do estabelecimento critérios para o diagnóstico (estudos e ensaios laboratoriais). Acreditamos que a gestão da conservação pode ser potencializada quando o monitoramento do estado de conservação estiver aliado às ciências da conservação e ao incentivo da utilização de novas tecnologias de levantamento do patrimônio e documentação.

Palavras Chave: diagnóstico; monitoramento; gestão da conservação

Abstract: STONE CONSERVATION MANAGEMENT IN BUILT HERITAGE - QUESTIONS AND PROPOSALS. This work aims to present a reflection on the challenges that the stone conservation field is currently facing in Brazil. We present the premises of good conservation practices, contexts in which all conservation and restoration works must necessarily be preceeded by conservations projects, where diagnostics surveys have a crucial function. We are trying to make explicit the key role of all the activities that are part of the diagnosis: we consider it as an important process of knowledge construction related to the deterioration assessment of immovable cultural properties, including stony materials. Legislation and methodologies available are also being discussed, as well the benefits of establishing criteria for the diagnosis (studies and laboratory tests). We believe that conservation management can be potentiated when monitoring is allied to the conservation sciences and the use of new recording and documentation technologies.

Keywords: diagnostics; monitoring; conservation management

\section{NATUREZA E METODOLOGIA DE UM PROJETO DE CONSERVAÇÃO}

A legislação recente ${ }^{1}$ (IPHAN, 2010), associada aos Manuais técnicos do IPHAN/Monumenta (GOMIDE, 2005) que tratam do conjunto da metodologia básica de elaboração de projetos de conservação e restauro de bens culturais imóveis, regulamenta o encaminhamento dos projetos para aprovação pelos órgãos de preservação. Para além das exigências impostas para se obter as licenças de obras, somos de opinião de que aprovar um projeto de conservação e restauro de um bem cultural imóvel diz respeito, também, à garantia de que haverá uma documentação adequada das intervenções que nele se pretende realizar ${ }^{2}$. Os projetos são compostos por três etapas básicas: levantamento, diagnóstico e projeto/ especificações. A primeira etapa, denominada "Identificação e conhecimento do bem" compõe-se basicamente de: pesquisa histórica, levantamentos cadastrais e arquitetônicos com identificação visual dos materiais. Destaca-se desta etapa a pesquisa histórica, a qual, em nossa opinião, quando associada à cronologia construtiva do bem cultural, identificando suas configurações espaciais e materiais ao longo do tempo, é extremamente

\section{doi: 10.18285/geonomos.v24i2.851}

\footnotetext{
Ver, em especial, o inciso III do Artigo 50 da Portaria IPHAN N ${ }^{\circ} 420 / 2010$, bem como os artigos 7o e 8․ <http://portal.iphan.gov.br/uploads/legislacao/ Portaria_n_420_de_22 de_dezembro_de_2010.pdf>.

Portaria_n_420_de_22_de_dezembro_de_2010.pdf>.
Ver, neste sentido, o importante trabalho de Haas (2003).
}

fecunda quando associada à pesquisa arqueológica.

Quanto ao Diagnóstico, os manuais existentes (ALMEIDA, 2005) fazem referência aos Mapas de Danos, que, para nós, consistem na realidade em representações gráficas de uma análise de percepção dos danos. Os manuais também prevêem prospecções arquitetônicas, as quais incluem remoção de amostras com o objetivo de se identificar os materiais. Essa análise pode ser enriquecida se, para além da caracterização, forem identificados também os produtos da alteração e da degradação dos materiais ${ }^{3}$. 0 diagnóstico ${ }^{4}$ propriamente dito visa, portanto, confirmar/refutar ${ }^{5}$ as hipóteses levantadas na fase de pré-diagnóstico na qual são feitos os mapeamentos de danos e alterações, posto que se funda num conhecimento mais aprofundado dos materiais e sistemas construtivos e de suas técnicas de execução e na caracterização dos materiais pétreos, das argamassas e de outros materiais (metais, cerâmicas, etc). É através dele que se tem condições de identificar os processos de deterioração, suas causas e seus mecanismos de ação. Some-se a isto a identificação de eventuais restaurações anteriores. Todos os dados do diagnóstico fornecem, portanto, as condições de se escolher materiais tradicionais

${ }^{3}$ Lembrando que não existe menção específica a este aspecto no Manual de Elaboração de Projetos do Programa Monumenta: o manual cita somente a necessidade de se identificar os agentes e causas dos danos (GOMIDE, 2005, p. 28).

${ }^{4}$ O diagnóstico se conclui, então, por relatórios consolidados relativos à caracterização dos materiais e ao seu estado de conservação, com base nos resultados dos ensaios in situ e no laboratório. Podem ser feitas análises destrutivas e, preferencialmente, não destrutivas. Todas devem ser justificadas e documentadas. ${ }^{5}$ ARCOLAO (2008). 
e/ou materiais novos, porém idôneos, isto é, compatíveis com os materiais históricos. Veremos adiante quais são as contribuições das ciências da conservação, no âmbito do diagnóstico, para a avaliação de compatibilidade dos materiais a serem usados nas obras de conservação.

Um projeto de conservação ${ }^{6}$, no nosso entender, consiste numa documentação sistematizada do conhecimento multidisciplinar acumulado e produzido sobre um bem cultural. Tem por objetivo informar as ações mínimas necessárias e orientar a execução em obras de intervenção, de modo que o bem cultural conserve aqueles valores que lhe foram atribuídos. Consiste na tradução destes valores em características espaciais, estruturais, materiais e estéticas que se pretende salvaguardar, ao mesmo tempo que desenha adequações para um uso seguro (e/ ou novo). Idealmente, deveria prever sempre o projeto de uma conservação continuada após as obras, que tratamos aqui como monitoramento do estado de conservação.

Dentro desta concepção de projeto de conservação, insistimos que o papel do diagnóstico é fundamental, como veremos no próximo tópico. O faseamento do projeto em etapas, como aquelas normatizadas pela $\mathrm{ABNT}^{7}$, permite um acercamento progressivo do bem cultural no que tange ao aprofundamento do conhecimento produzido e sistematizado sobre ele. Estas etapas também organizam as fases de aprovação do conjunto dos projetos (IPHAN, 2010), de modo que as exigências a serem cumpridas podem ser cumpridas e verificadas na etapa sucessiva. Entretanto, a execução de obras em um bem cultural imóvel tombado somente é autorizada pelo IPHAN após a aprovação da do projeto executivo e sem nenhuma ressalva.

\section{CRITÉRIOS E UTILIDADE DO DIAGNÓSTICO NO PROJETO DE CONSERVAÇÃO DE BENS CULTURAIS IMÓVEIS}

O grande valor do diagnóstico reside na oportunidade de se construir conhecimento multidisciplinar $^{8}$ a respeito do processo de alteração, degradação e deterioração ${ }^{9}$ de um bem

\footnotetext{
Estamos de acordo com a terminologia da teoria contemporânea da conservação. Portanto, consideramos que a restauração é uma abordagem específica que se encontra dentro do âmbito da conservação (MUÑOZ-VIÑAS, 2005).

De acordo com a norma NBR 13532:1995, são etapas básicas de um projet arquitetônico, âmbito no qual se insere o projeto de restauro: o estudo preliminar, anteprojeto e o projeto executivo. Tomemos como exemplo o Termo de Referência do edital de licitação dos projetos de restauração do prédio sede da SE-IPHAN-RJ. Para cada projeto (incluindo o da fachada), foram previstos os seguintes produtos organizados por etapas: Estudo Preliminar; Anteprojeto; Projeto Executivo; Caderno de

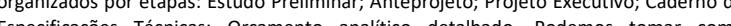
referencia outros projetos tambem, como os Projetos de Consolidaça das Runas do eferência outros projetos tambem, como os Projetos de Consolidaca Ruínas do Convento de São Boaventura (Itaboraí, RJ), aprovados por etapas pelo IPHAN e INEPAC em 2012.

${ }^{8}$ Vide Assumpção et ali (2010) e Gallois, 2014.

Tomemos as definições dos termos usados pelo ICOMOS: Alteração. "Qualquer modificação do material. Não implica necessariamente um piorar das suas características do ponto de vista conservativo. Por exemplo, um revestimento reversível aplicado sobre uma pedra pode ser considerado uma alterac̃o", Dano: "Percepão

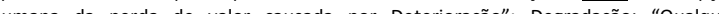
modificação física ou química das propriedades intrínsecas da pedra que cause perda de
}

cultural. O diagnóstico é base e ponto de referência para planejar e desenhar a intervenção de conservação, de modo que se consiga aproximar ao máximo das condições de colocar em prática as premissas éticas do projeto da conservação calcadas aqui na materialidade do bem cultural dentre as quais destacamos: a autenticidade, a reversibilidade/ retratabilidade ${ }^{10}$ e a mínima intervenção ${ }^{11}$. Para que tais princípios se materializem na intervenção, existe outro princípio, o da compatibilidade, para a qual a ciência da conservação (TORRACA, 2005, 2009; BIGAS, 2009) tem as maiores contribuições a dar ${ }^{12}$. Para compreender o que significa compatibilidade entre a pedra e outros materiais, destacamos uma explicação geral, proposta por Bigas (2009, p. 93):

A pedra, em geral, não tem incompatibilidade sistemática com os demais materiais de construção tradicionais. Entretanto, segundo sua natureza, suas propriedades e dentro de algumas condições ambientais, ela tem sua durabilidade reforçada ou diminuída na presença de certos materiais. Assim é que numerosas degradações têm sua origem na coexistência de materiais com comportamentos diferentes. $^{13}$

Uma segunda definição do princípio de compatibilidade, mais específica, é dada por Torraca (2009, p. 69):

Hoje, a maioria dos especialistas em restauração na Europa guia-se pelo princípio de compatibilidade, indicando que os materiais utilizados no restauro devem ser compatíveis com os originais, isto é, não deveriam lhes causar danos e sim contribuir para a sua conservação. Em outras palavras, pode-se dizer que os materiais originais e aqueles adicionados na restauração devem formar uma estrutura compósita que apresenta um comportamento "satisfatório" sob a pressão criada pelo ambiente que esta estrutura compósita irá enfrentar. Pelo termo "satisfatório" entende-se que o aparecimento inevitável de um novo processo de deterioração deve ser postergado por tanto tempo quanto possível e que é o material de restauração aquele que deve ser o primeiro a falhar ${ }^{14}$.

Sob pretexto de se buscar a necessária compatibilidade na conservação, não se deve fazer

valor ou restrições ao uso"; Deterioração: "Sofrer ou infligir uma redução da qualidade, valor, carácter, etc.; depreciação”. (VERGÈS-BELMIN, 2008: Versão Inglês/Português, 2016, p.8).

${ }^{10}$ A retratabilidade foi discutida como alternativa viável da reversibilidade pelo Professor Delgado Rodrigues no Curso de Conservação e Caracterização da Pedra (LABTEC Rochas/IGC/UFMG e IPHAN, Belo Horizonte, 2014). Ver também as considerações de Aguiar (2003) a respeito da reversibilidade.

${ }^{11}$ Outro princípio importante, a distingüibilidade das intervenções, é objeto de muitas
Ongães de discussões no âmbito da conservação arquitetônica, tanto pelos seus aspectos estéticos quanto de conservação e compatibilidade dos dos materiais (BIGAS, 2009, p.93).

${ }^{12}$ Explicitando e provando através de ensaios, por exemplo, como pode ser inadequado usar revestimentos a base de cimento, altamente impermeáveis, em alvenarias históricas. Elas impedem as trocas de vapor e intensificam os problemas decorrentes da umidade ascendente (contaminação por sais, desagregação dos materiais, etc). ${ }_{13}^{13}$ Tradução livre nossa.

${ }^{14}$ Tradução livre nossa. Grifo nosso. 
ensaios em excesso. Cada ensaio deve ter uma justificativa (quantidade, localização, motivo) e, sobretudo, estar orientado a uma finalidade concreta $^{15}$, que é a intervenção de conservação ${ }^{16}$. Além dos ensaios de caracterização da pedra, os quais incluem a mensuração de sua porosidade, dureza, resistência à flexão e à compressão, outro ensaio se faz bastante útil: detectar fissuras internas através de ensaios não destrutivos como os ultrasons. Dentre os objetivos específicos de um plano de ensaios, destacam-se os seguintes, ligados aos aspectos da degradação: perda de massa, ataque por sais, identificação de sujidades e necessidade de consolidação da pedra. Tendo em vista a água ser o maior fator de degradação dos materiais porosos, são cruciais também aqueles ensaios que permitam compreender o comportamento da água dentro dos materiais: absorção, migração, transporte de sais, evaporação, permeabilidade ao vapor de água, ciclo de molhagem e secagem, dentre outros (TORRACA, 2005; BIGAS, 2009). Estes últimos ensaios são também fundamentais para a avaliação do desempenho e eficácia de produtos de consolidação e proteção (ex. hidrofugantes), desde que já tenham sido considerados compatíveis com os substratos. É necessário se destacar que na prática corrente na conservação no Brasil normalmente se escolhem produtos segundo seu uso mais freqüente, com base em marcas e características tidas como idôneas, não sendo precedidos, necessariamente, por estudos prévios em laboratório. Há, portanto, muitas frentes de pesquisa de avaliação de compatiblidade e eficácia química e física entre materiais históricos e materiais de conservação (limpeza, consolidação, proteção), dada a grande variedade de pedras presentes no patrimônio construído brasileiro. A aplicação prática de tais estudos à conservação dos bens imóveis, consiste em demonstrar se os produtos são idôneos e eficazes ao que se propõem $^{17}$. Ao nosso ver, esta é, justamente, uma das frentes de trabalho mais fecundas das ciências da conservação aplicadas aos bens imóveis no Brasil, com especial atenção à conservação da pedra.

Desta forma, podemos afirmar aqui que o diagnóstico também permite estabelecer critérios de "controle de qualidade" da conservação a ser realizada; além de indicar as condições (ex. ambientais) para conservação preventiva. Os ensaios permitem o estabelecimento de uma matriz ${ }^{18}$ de parâmetros para comparação a serem usados no monitoramento do estado de conservação

\footnotetext{
${ }^{15}$ Cf anotações de aula "Apresentação das propriedades físicas e mecânicas mais relevantes dos materiais pétreos", 02/12/2014, Prof. José Delgado Rodrigues (Curso de Conservação e Caracterização da Pedra, LABTEC Rochas/IGC/UFMG e IPHAN, Belo Horizonte, 2014).

Podemos dizer que se trata de uma abordagem que se identifica com a argumentação pragmática da conservação científica (MUÑOZ-VINÃS: 2005, p.88).

${ }^{17}$ Estudos com protetivos a serem aplicados em pedras estão sendo realizados no CETEM - Centro de Tecnologia Mineral. Foram iniciados após o Acordo de Cooperação TÉcnica do CETEM com o IPHAN-RJ. Vide também Gallois (2015).

Técnica do CETEM com o IPHAN-RJ. Vide também Gallo
${ }_{18}$ Para a matriz, vide Revez, Delgado Rodrigues (2015).
}

posteriormente à obra: o diagnóstico é portanto ferramenta decisiva para avaliar a qualidade e a durabilidade das ações de conservação. Daí a importância das ações de manutenção e conservação preventivas serem realizadas de forma planejada e periódica posteriormente à obra: tratase do monitoramento do estado de conservação, como veremos adiante.

\section{O PROJETO DE CONSERVAÇÃO COMO PRODUÇÃO DE CONHECIMENTO}

\subsection{Qualidade dos projetos}

Segundo Delgado Rodrigues (2014), os padrões de deterioração são as consequências visíveis do impacto das condições ambientais em objetos em pedra: os padrões dependem do tipo e da severidade dos agentes externos, do tipo de substrato e da sua vulnerabilidade. Segundo Delgado Rodrigues (op cit), nem sempre os padrões visíveis (que desenhamos na forma de Mapa de Danos) são suficientes para interpretar a situação. Corrobora com esta opinião Arcolao (2008) ${ }^{19}$ que estabelece então uma metodologia, já estudada por nós (2014) para o diagnóstico. Na elaboração do projeto de conservação, em diálogo com o diagnóstico, deve-se levar em conta que, embora algumas degradações tenham causas diferentes, seus efeitos acabam por ter tratamentos semelhantes em função de sua intensidade ${ }^{20}$ e extensão. Por outro lado, no caso de perdas de material, um procedimento básico de consolidação costuma ser utilizado para cada um dos três efeitos ou sinais visíveis de desprendimento de material por perda de grãos, ou por camadas ou por placas (DELGADO RODRIGUES, 2014). Portanto, como pudemos já verificar também nas nossas ações de acompanhamento e fiscalização de obras de conservação de bens tombados federais no RJ no âmbito da Superintendência do IPHAN-RJ, não há uma correlação direta entre a origem da degradação, sua manifestação na superfície dos materiais na forma de danos (percebidos) e a intervenção de conservação. É neste espaço que fazse necessária a sensibilidade do conservadorrestaurador, e da fiscalização do órgão de preservação, na revisão e ajustes dos tratamentos propostos. Daí a relevância, na gestão da conservação, de se prover condições e recursos nacessários para execução da totalidade do projeto (diagnóstico e especificações) antes da obra. Necessita-se de tempo para realizar os ensaios que busquem compreender as origens e causas dos danos visíveis, bem como para verificar a eficácia e

\footnotetext{
${ }^{19}$ Para maiores detalhes de uma metodologia analítica para o pré-diagnóstico e diagnóstico, ver o trabalho de Arcolao (2008, p.35), que explora a ideia dos "sinais diagnósticos" como "provas e indí́ios" através do reconhecimento, identificação e classificação das modificações na superfície dos materiais porosos através da visão, do tato, do olfato e do gosto. Expusemos esta metodologia em Gallois (2014).

${ }_{20}^{20}$ Assim é que se aplicam procedimentos de limpeza de diferente intensidade em função do tipo e do grau de sujidade. Vide Assumpção et ali (2010).
} 
os riscos de incompatibilidade das alternativas de tratamentos de limpeza ${ }^{21}$, consolidação e proteção. Quando da apresentação do projeto executivo de conservação, os tratamentos inicialmente propostos em fases de aprovação preliminares (ex. Estudo Preliminar), já deverão estar revistos/redefinidos ou confirmados, com base na conclusão do diagnóstico, isto é, após os estudos conclusivos em termos de risco de incompatibilidade e eficácia ${ }^{22}$. Propusemos este faseamento no Termo de Referência para a contratação de projetos para a sede do IPHAN-RJ, organizando por etapas os ensaios e análises a serem realizados pelo CETEM $^{23}$. O que baseou nossa proposta foi a consciência de que a qualidade das ações de conservação está intimamente ligada à qualidade dos projetos, bem como à eficiência e transparência na gestão da conservação.

Um bem cultural imóvel pode ser comparado a um grande artefato $^{24}$ inserido no meio urbano, de onde se deduz o papel crucial das superfícies para a conservação do bem cultural: são elas a interface do bem com o seu ambiente ${ }^{25}$ e com o transcurso no tempo deste artefato. As superfícies são tidas pelos especialistas (ARCOLAO, 2008; LAZZARINI, TABASSO, 1986), como "zonas de contato" entre o bem cultural e o meio em que se encontra. Para além das aparências, as superfícies revelam uma série de dados, cabendo justamente ao Mapa de Danos representá-las (identificação inicial, porém sistemática) e ao diagnóstico, analisar. São esses dados que fornecerão pistas sobre as causas dos processos de degradação e deterioração dos bens culturais (além, é claro, da identificação das intervenções anteriores). Para além do caráter relativo à deterioração das superfícies arquitetônicas, há que se considerar o caráter histórico destas últimas: "Os revestimentos estratificam a história sedimentada destas 'apresentações visuais' da arquitectura ao longo da história, constituindo provas materiais de primeira importância sobre as modificações nas formas de comunicação arquitectural” (AGUIAR, 2003, p. 8).

Os parâmetros de qualidade do projeto de conservação estão, portanto, relacionados ao registro acurado e detalhado do estado de conservação, daí o Mapa de Danos ser um dos elementos-chave do projeto de conservação. Além de um desenho gráfico preciso das propostas de

\footnotetext{
${ }^{21}$ Para este tópico específico, ver o importante trabalho de Revez e Delgado Rodrigues (2015).

${ }_{22}$ Revez; Delgado Rodrigues (2015) propuseram uma matriz bastante interessante de avaliação em termos de risco e eficácia.

${ }^{23}$ Os critérios específicos de risco e eficácia, para os ensaios da fachada do IPHAN-RJ, devem ser estudados e aprofundados conjuntamente com o CETEM.

${ }^{24}$ Tomemos a definição de artefato advinda do campo da arqueologia histórica: "Os artefatos são a encarnação tangíveis das relações sociais, incorporando atitudes comportamentos do passado" (BEAUDRY et ali, 2007, p. 73).

${ }^{25}$ Seja o ambiente urbano considerado do ponto de vista morfológico (ex., lugar no processo tipológico do tecido urbano), seja do ponto de vista ambiental ligado às condições climáticas e impactos da poluição atmosférica.
}

intervenção ${ }^{26}$, é fundamental que se documente detalhadamente as intervenções efetivamente realizadas (documentação as-built, a ser realizada na obra), de forma que no futuro se possa conhecer bem o que se passou nesses "grandes artefatos" ${ }^{27}$.

\subsection{Metodologia para mapeamento de danos e} alterações

Levando-se em consideração que os sinais visíveis a olho nu podem ser a combinação de um ou mais processos de degradação, discutimos em trabalho anterior (GALLOIS, 2014) que a organização gráfica dos Mapa de Danos propiciasse uma leitura facilitada dos danos e de suas correlações se organizada em pranchas distintas por classe de danos. Utilizamos esta metodologia para os projetos de conservação da fachada do prédio da sede do IPHAN-RJ na elaboração do termo de referência para licitação dos projetos de conservação e restauração arquitetônica deste prédio $^{28}$. Para subsidiar o Termo de Referência supracitado, foi feita uma pesquisa prévia de custo-benefício de diferentes métodos e técnicas de levantamento arquitetônico, a base para os Mapas de Danos, a saber: levantamento manual (incluindo mobilização e montagem de andaimes), laser scanning $3 D$ e fotogrametria, tendo sido a fotogrametria o método ${ }^{29}$ escolhido para realizar o levantamento arquitetônico da fachada.

\section{MONITORAMENTO DO ESTADO DE CONSERVAÇÃO DE BENS CULTURAIS IMÓVEIS}

Tomamos como referência aqui o processo de elaboração do projeto de manutenção e conservação do monumento ao Cristo Redentor (RJ), conduzido a partir de 2011 com base nos critérios e na metodologia que estipulamos no Iphan-RJ para o desenho do projeto de monitoramento do estado de conservação a ser encaminhado ao Iphan. Aqui, entendemos monitoramento como o conjunto das ações que têm por objetivo avaliar e quantificar o

\footnotetext{
${ }^{26}$ Tomemos como referência os projetos de consolidação do Bem Tombado Federal Ruínas do Convento de São Boaventura, Itaboraí-RJ, aprovados pelo IPHAN-RJ e INEPAC (Instituto Estadual do Patrimônio Cultural) em 2012.

${ }^{27}$ Esta é uma ideia que Letellier (2007) defende também.

${ }^{28}$ Bem tombado nacional e importante exemplar da arquitetura eclética. Este termo de referência teve como objetivo, dente outros, prover todos os subsídios técnicos e científicos necessários à execução da obra de conservação e restauro, especialmente para a fachada e do prédio sede do IPHAN-RJ, ricamente ornamentada em cantaria e ara a Associs, venedora da liciça dos de análises e ensaios de caracterização da cantaria e das argamassas da fachada estão sendo feitos pelo CETEM. Outro exemplo de aplicação da metodologia que propusemos em 2014, foi a readequação da formatação dos mapas de danos dos projetos de conservação das fachadas do bem tombado nacional Mosteiro de São Bento apresentados à SE-IPHAN/RJ entre 2013/2014. Para este projeto, solicitamos análises do estado de conservação das cantarias e das argamassas de revestimento (realizadas pelo CETEM), não previstas inicialmente pela construtora. 0 trabatho se iniciou pelo trecho posterior das fachadas do Mosteiro, aquelas mais expostas aos poluentes atmosféricos da antiga Perimetral e ao spray salino da baía de Guanabara.

atmosféricos da antiga Perimetral e ao spray salino da baía de Guanabara.
${ }^{29}$ Tomamos como base de referência nesta escolha a qualidade dos levantamentos ${ }^{29}$ Tomamos como base de referência nesta escolha a qualidade dos levantamentos
(ortofotos) que já tinham sido realizados para os Projetos de Consolidação das Ruínas do Convento de São Boaventura, Itaboraí, RJ. Os levantamentos mais recentes da fachada do prédio da sede do IPHAN-RJ, no contrato com Archi5 Arquitetos Associados, foram realizados pelo arquiteto e fotógrafo Adolfo Ibañez Vila. Apresentaram resultados além do estipulado pelo edital: com o auxilio de drones, os levantamentos resultaram em um trabalho de fotogrametria em três dimeñões de altíssima resoluça Neste

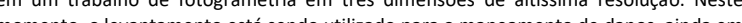
momento, o levantamento está sendo utilizado para o mapeamento de danos, ainda em fase de elaboração.
} 
progresso e a velocidade da degradação e da deterioração ${ }^{30}$. O monitoramento é uma atividade de gestão da conservação nada usual, porém fundamental, para se prever o escopo básico de manutenção, bem como os meios de se detectar antecipadamente os momentos em que ações de conservação (incluindo restauração) serão necessárias. Desta forma, busca viabilizar, de fato, uma conservação preventiva que dê conta dos bens culturais imóveis em sua integralidade (no caso do Cristo Redentor, estas diretrizes são essenciais, tendo em vista as condições ambientais extremas em que se insere o bem).

Destacamos alguns a seguir alguns dos parâmetros essenciais de um projeto de monitoramento: deve ter frequência regular e, para sua efetivação, devem ser escolhidas áreas-teste, determinando-se um ponto-zero para as observações, análises e mensurações. As áreas-teste devem ser escolhidas juntamente com a fiscalização e ser representativas do ponto de vista das características da degradação do bem. Deve-se utilizar a documentação elaborada na fase de Diagnóstico, de forma que os Mapas de Danos sejam utilizados como os referenciais gráficos obrigatórios para os registros realizados durante 0 monitoramento. Tais registros devem ser atualizados periodicamente assim que for detectada um significativa e/ou nova evolução dos danos e alterações. Evidentemente, deve prever em seu planejamento o acesso seguro das equipes ${ }^{31}$ e ter custos viáveis (daí a necessidade do Plano de Ensaios atender a objetivos precisos).

Conforme o que expusemos até aqui, a gestão da conservação de bens culturais pode ser potencializada no momento em que a conservação preventiva $^{32}$ incluir em seu planejamento atividades de monitoramento do estado de conservação associadas à produção de conhecimento no campo das ciências da conservação. Desta forma, verifica-se que a documentação do projeto de conservação passa a alargar seus objetivos para além das aprovações e licenças, ganhando status de ferramenta de gestão da conservação. Sendo assim, há que se explorar as possibilidades em aplicações que cada uma das técnicas de levantamento hoje disponíveis (fotografia, fotogrametria 2D e 3D, laser scanning $3 D$ ) podem apresentar não só para a elaboração de projetos $^{33}$ como para o monitoramento periódico do estado de conservação dos bens culturais: trata-se de usar as tecnologias em favor de um olhar conservativo.

\footnotetext{
${ }^{30}$ Para a discussão sobre os diferentes sentidos de dano, deterioração e degradação, vide Gallois (2014).

${ }^{31}$ Atendendo às normas do Ministério do Trabalho, em especial, a NR18.

${ }^{32}$ Adotamos a abordagem de De Barros Gonçalves et ali (2008, p.5 e p. 11), do ICOM-CC

(2008) e de Muñoz-Vinãs (2005), para quem toda a conservação é preventiva (p.22).

${ }_{33}$ Merecem serem estudadas outras metodologias de projeto tridimensionais, para além da plataforma CAD.
}

\section{O PAPEL DO PROJETO E DAS CIÊNCIAS DA CONSERVAÇÃO NA GESTÃO DA CONSERVAÇÃO DOS BENS CULTURAIS}

Dentre as mais importantes ações voltadas à consolidação das ciências da conservação, podemos destacar a necessária cooperação técnica ${ }^{34}$ entre órgãos de patrimônio e centros de pesquisa nas áreas da geologia, química, biologia, conservação e arquitetura de maneira a ampliar o campo da ciência da conservação aplicada ao patrimônio construído no Brasil. Também podemos destacar a necessária normatização para realização de análises e ensaios de materiais históricos porosos ${ }^{35}$, como as pedras e as argamassas antigas, bem como a divulgação científica compartilhada, interinstitucional e multidisciplinar $^{36}$. Outra frente de trabalho, não menos importante, a ser levada a cabo pelos órgaos de preservação, com a colaboração das empresas de restauro, é a elaboração de composições de custos que possam dar maior transparência, padronização e agilidade na orçamentação de projetos e obras de conservação $^{37}$. Se ampliar e consolidar o campo da conservação do patrimônio construído pela via da ciência $^{38}$ e da engenharia de custos se faz necessário no país, há também alguns caminhos a percorrer novamente. Dentre eles, destacamos os cursos de formação profissional de mão-de-obra para a conservação e restauro de bens imóveis que buscam recuperar os saberes tradicionais dos mestres artífices, em especial os canteiros ${ }^{39}$.

Este texto tratou de forma sintética da natureza do projeto de conservação de bens culturais, no qual a pedra se insere como um dos materiais que merecem especial atenção, por ser um material de difícil reposição e também produto de uma longa e complexa história geológica, associada à geomemória $^{40}$. Foram apresentadas as premissas das boas práticas de gestão da conservação dos bens culturais imóveis, que passam, necessariamente, por um projeto partilhado de construção de conhecimento, com todas as etapas que envolvem a elaboração dos estudos diagnósticos, especificações,

\footnotetext{
${ }^{34}$ Destacamos o Acordo de Cooperação Técnica da Superintendência do IPHAN/RJ com o Centro de Tecnologia Mineral, que tem por objetivo principal produzir conhecimento acerca do estado de conservação dos materiais porosos (pedra, argamassa) dos bens culturais imoveis tombados em nível feredal no Rio de Janeiro e analisar as metodologias de intervenção que atendam aos princípios éticos da conservação metodologias de intervenção que atendam aos principios éticos da conserva
(autenticidade material, retratabilidade, mínima intervenção, compatibilidade). ${ }^{35}$ Este tópico é objeto do Termo de Cooperação Técnica IPHAN-RJ/CETEM. ${ }^{36}$ Concordamos plenamente com Froner (2011).

${ }^{37}$ Ensaios laboratoriais, diferentes técnicas de levantamentos - laser scanning $3 D$ fotogrametria; diagnostico; obras por classe de intervenção (limpezas, consolidações, proteções, manutenções, etc.).

${ }^{38}$ Para uma avaliação da relação entre as ciências da conservação e o campo da conservação dos bens culturais, em especial acervos culturais, vide Froner (2011).

conservação dos bens culturais, em especial acervos culturais, vide Froner (2011).
39 Vide referência às Oficinas de Cantaria do "Seu Juca", mestre canteiro de Ouro Preto Vide referência às Oficinas de Cantaria do "Seu Juca", mestre canteiro de Ouro Preto
(PEREIRA ET ali, 2007, pp.91-99). No RJ, podemos destacar os Cursos de qualificação profissional para o restauro e a conservação arquitetônica da cidade do Rio de Janeiro realizados entre 2006 e 2007 (Programa Monumenta, Prefeitura da Cidade do Rio de Janeiro, UNESCO, BID).

${ }^{40}$ Vide Palestra "Patrimônio Geológico Construído: conservação de monumentos preservação de memórias" proferida pelo Prof. Dr. Antônio Gilberto Costa (LABTEC Rochas/IGC/UFMG) no Seminário "Rochas ornamentais em bens históricos tombados e Inauguração do Laboratório de Conservação e Alterabilidade de Materiais de Construção" no CETEM, Rio de Janeiro, em 16/09/2016.
} 
acompanhamento e fiscalização de obras e da documentação as-built da intervenção de conservação, além do monitoramento pós-obra.

Tratou-se de se pensar também nos objetivos da gestão da conservação enquanto gestão da informação ${ }^{41}$, calcada em projetos de conservação vistos como documentos públicos. O valor da documentação do patrimônio reside no fato desta ser, também, uma ferramenta de transparência pública no planejamento e na tomada de decisões na conservação do patrimônio material (na qual se espera a participação de um âmbito maior da sociedade civil). A gestão da conservação tem, portanto, como objetivo principal dar as condições de se fortalecer as decisões de conservação a partir do compartilhamento de saberes.

\section{REFERÊNCIAS BIBLIOGRÁFICAS}

ABNT: NBR 13532:1995. Elaboração de projetos de edificação Arquitetura.

ALMEIDA, F. Manual de Conservação de Cantarias. 1a ed. Brasília: IPHAN/Programa Monumenta: 2005.

AGUIAR, J. Dos problemas aos conceitos: conservação, restauro e renovação de revestimentos exteriores, em centros históricos. 10 PATORREB, Porto, FEUP: 2003.

ARCOLAO, C. La diagnosi nel restauro architettonico. Techniche, procedure, protocolli. Venezia: Marsilio, 2008.

ASSUMPÇÃO, M.; CAPANEMA, E.; GALLOIS, C.J.S. Restauração de Cantarias, uma visão multidisciplinar: o caso do Antigo Tribunal Regional Eleitoral In Anais do III Congresso Internacional na Recuperação, Manutenção e Restauração de Edifícios. Rio de Janeiro, Escola Politécnica, UFRJ: 2010.

BEAUDRY, M.C.; COOK, L.J.; MROZOWSKI, S.A. Artefatos e vozes ativas: cultura material como discurso social. Vestígios. Revista Latino-Americana de Arqueologia Histórica. Vol. 1. N. 2, pp. 73-113, jul-dez. 2007.

BIGAS, J.P. (éd.). Pierre et Patrimoine. Connaissance et Conservation. Arles: Actes Sud / CEFRACOR, 2009.

BRASIL. Ministério da Cultura. PATRIMÔNIO HISTÓRICO E ARTÍSTICO NACIONAL - IPHAN. Portaria no 420, de 22 de dezembro de 2010.

DE BARROS GONÇALVES, W.; SOUZA, L. A. C.; FRONER, Y.A Tópicos em conservação preventiva - 6. Edifícios que abrigam coleções. Belo Horizonte: LACICOR, EBA, UFMG: 2008.

DELGADO RODRIGUES, J. Defining, mapping and assessing deterioration patterns in stone conservation projects, Journal of Cultural Heritage, 2014. Disponível em: <http://dx.doi.org/10.1016/j.culher.2014.06.007> (article in press).

FRONER, Y.-A. Conservação e restauração: a legitimação da ciência. Acervo, v. 23, n. 2, pp. 47-56, 2011.

GALLOIS, C.J.S. A importância do diagnóstico nos projetos conservação e restauro arquitetônico. Proposta de normatização para mapeamento de danos em materiais pétreos naturais e artificiais. VI Oficina de Pesquisa do IPHAN

41 Gestão da Informação: "Processo que envolve encontrar, catalogar, armazenar compartilhar informações, tornando-as acessiveis aos usuários potenciais hoje e no futuro". (Letellier, 2007, xv, tradução livre nossa). patrimônio e legislação. Rio de Janeiro: COPEDOC/IPHAN, 2014 (2016).

GALLOIS, C.J.S. A pichação de bens culturais como problema de conservação urbana. In Anais do 70 Seminário Mestres e Conselheiros: Agentes Multiplicadores do Patrimônio. "Patrimônio e Cidades". Belo Horizonte: IEDS, Instituto Metodista Isabela Hendrix, UFMG, IEPHA, IPHAN, 2015.

GOMIDE, J.H., SILVA, P.R.; BRAGA, S.M.N. Manual de elaboração de projetos de preservação do patrimônio cultural. Brasília: Programa Monumenta, MinC, 2005.

HAAS, Y.C. Tecnologia da Conservação de pedras: Uma sistematização de procedimentos para conservação dos elementos de fachada. Dissertação (mestrado) - UFRJ/ PROARQ. Rio de Janeiro: UFRJ/ FAU, 2003.

ICOM-CC. Terminología para definir la conservación del patrimonio cultural tangible. Traducción al español de la resolución adoptada por los miembros de ICOMCC durante la 15a Conferencia Trienal. New Delhi, 22-26 de septiembre de 2008. Disponível em <http://www.icomcc.org/54/document/icom-cc-resolucion-terminologiaespanol/?id=748\#.WDWMBrIrJ0w>. Acesso em 14/10/16.

LAZZARINI, L.; TABASSO, M.L. II restauro della pietra. Padova: CEDAM, 1986.

LETELLIER, R. Recording, Documentation and Information Management for the Conservation of Heritage Places. Guiding Principles. Los Angeles: The Getty Conservation Institute, 2007. Disponível em < https://www.getty.edu/conservation/publications_resources /pdf_publications/pdf/guiding_principles.pdf>. Acesso em out./2016

MUÑOZ-VIÑAS, S. Contemporary Theory of Conservation. Oxford: Elsevier Butterworth-Heinemann, 2005.

MUSSO, S. (org.) Recupero e Restauro degli Edifici. Guida Pratica al rilievo e alla diagnostica. III Edizione. Roma: EPC, 2010.

PEREIRA, C.A.; LICCARDO, A.; GOMES DA SILVA, F. A Arte da Cantaria. Belo Horizonte: UFOP, Ed. C/Arte, 2007.

REVEZ, M.J.; DELGADO RODRIGUES, J. Incompatibility risk assessment procedure for the cleaning of built heritage, Journal of Cultural Heritage, 2015. Disponível em: <http://dx.doi.org/10.1016/j.culher.2015.09.003> (article in press).

TORRACA, G. Porous Building Materials. Roma: ICCROM, 2005 (3ed. 1998).

TORRACA, G. Lectures on material science for architectural conservation. Los Angeles: The GETTY Conservation Institute, 2009.

VERGÈS-BELMIN, V. (Ed.). Illustrated glossary on stone deterioration patterns glossário ilustrado das formas de deterioração da pedra. English-Portuguese Version / Versão Inglês-Português, Portuguese translation of the EnglishFrench edition of 2008. Tradução portuguesa da versão inglês-francês de 2008 por José Delgado Rodrigues e Maria João Revez (2016). Paris: ICOMOS-ISCS, 2008. Disponível em< http://www.icomos.pt/images/pdfs/Glossario_Pedra_Icomos .pdf>

Contribuição ao

1‥ Simpósio Brasileiro de Caracterização e Conservação da Pedra 14 a 16 de dezembro de 2016, Congonhas - MG

Nota:

É de responsabilidade da comissão editorial do Simpósio a revisão gramatical, ortográfica, de citações e referências bibliográficas. As normas de submissão podem se diferenciar das desta revista. 